\title{
A hospital outbreak of penicillin-resistant pneumococci in The Netherlands
}

\author{
C.M.P.W. Mandigers*, R.J.A. Diepersloot**, M. Dessens ${ }^{+}$, \\ S.J.M. Mol*, B. van Klingeren+
}

A hospital outbreak of penicillin-resistant pneumococci in The Netherlands. C.M.P.W. Mandigers, R.J.A. Diepersloot, M. Dessens, S.J.M. Mol, B. van Klingeren. CERS Journals Ltd 1994.

ABSTRACT: Respiratory infections with penicillin resistant pneumococci constitute an increasing health care problem. This paper describes the nosocomial spread of penicillin resistant pneumococci (PRP) on a pulmonary ward.

During an eight-month period, minimal inhibitory concentrations (MICs) for penicillin and several other antibiotics were performed on all Streptococcus pneumoniae isolates that were shown to be penicillin resistant by a screening assay. The personal data and case history of all patients with penicillin resistant pneumococci were evaluated.

Penicillin Resistant Pneumococci were cultured from 18 patients, 16 men (mean age $74 \pm 8$ yrs) and 2 women (aged 54 and $60 \mathrm{yrs}$ ). Chronic obstructive pulmonary disease was diagnosed in 16 patients, 10 of which had an additional underlying disease ( 2 diabetes mellitus, 2 heart failure, 2 malignancy).

Prior to culture of Penicillin Resistant Pneumococci, 11 out of 18 patients were treated with antibiotics, a $\beta$-lactam in most instances. Ten out of 18 patients died during or shortly after hospitalization. The death of one patient seems to be directly related to infection with Pencillin Resistant Pneumococci. The five Penicillin Resistant Pneumococci isolates available for serotyping were all type 9. The minimal inhibitory concentrations for penicillin varied from 0.5 to $2.0 \mathrm{mg} \cdot l^{-1}$. High minimal inhibitory concentrations were also noted for cefixime (all over $4.0 \mathrm{mg} \cdot \boldsymbol{l}^{-1}$ ) and ceftriaxone $\left(0.5-1.0 \mathrm{mg} \cdot l^{-1}\right)$.

It is concluded that penicillin resistant pneumococci can spread rapidly among old and debilitated patients. Thus, patients with this infection should be barrier nursed.

Eur Respir J., 1994, 7, 1635-1639.
*Dept of Internal Medicine, St Joseph Hospital, Veldhoven, The Netherlands. ** Laboratory of Medical Microbiology, Diakonessenhospital, Utrecht, The Netherlands. +Laboratory for Bacteriology and Antimicrobial Agents, RIVM, Bilthoven, The Netherlands.

Correspondence: R.J.A. Diepersloot Laboratory for Medical Microbiology Diakonessenhospital

Bosboomstraat 1

3582 KE Utrecht

The Netherlands

Keywords: Antibiotic resistance nosocomial infection

Streptococcus pneumoniae

Received August 31993

Accepted after revision May 191994
Since the introduction of benzyl-penicillin in the 1940s, this antibiotic has remained the treatment of choice in infections caused by Streptococcus pneumoniae (pneumococci). Initially the minimal inhibiting concentrations (MICs) were in the range of $0.006-0.008 \mathrm{mg} \cdot l^{-1}$. Over time, the MICs of clinical isolates gradually increased [1]. In 1967, the first penicillin-resistant pneumococci (PRP) were reported in Australia and subsequently in Papua New-Guinea [2, 3]. These isolates showed MICs of $0.1-1.0 \mathrm{mg} \cdot l^{-1}$. In 1978 , in South-Africa pneumococci were discovered with a more serious resistance (MIC $\geq 1.0$ $\left.\mathrm{mg} \cdot l^{-1}\right)$ [4]. Since then, penicillin-resistance has been divided into low level resistance (i.e. MIC $0.1-1.0 \mathrm{mg} \cdot l^{-1}$ ) and high level resistance (i.e. MIC $>1.0 \mathrm{mg} \cdot \mathrm{l}^{-1}$ ).

During the last decade, PRP have spread all over the world [5]. In South-Africa, Israel, the United States of America and France, over $10 \%$ of the isolated pneumococci appear to be penicillin-resistant, whereas in Spain and Hungary, this percentage has increased to $30-50 \%$ [6-12].

In The Netherlands less than $1 \%$ of all pneumococci appear to be resistant to penicillin [13]. Recently, however, PRP spread on the pulmonary ward of the St Joseph's Hospital in Veldhoven, in the southern part of the Netherlands. The outbreak is described in this report.

\section{Methods}

In the Laboratory for Public Health in Veldhoven, The Netherlands, all isolated $\alpha$-haemolytic streptococci were identified as being Streptococcus pneumoniae using an optochine disk. All cultured pneumococci were inoculated on isosensitest agar plates supplemented with $0.05 \mathrm{mg} \cdot \mathrm{l}^{-1}$ penicillin. In case of growth, a MIC was determined by the agar dilution method (isosensitest agar with 5\% heated sheep blood). Penicillin-resistant pneumococci, cultured from patients admitted to the pulmonary ward of the St. Joseph's Hospital from November 1990 up to May 1991, were further tested in 
the Laboratory for Bacteriology and Antimicrobial Agents of The National Institute of Public Health and Environmental Protection (RIVM).

\section{Sensitivity testing}

MIC determinations were performed by inoculating $10^{4}$ colony forming units (cfu) on blood agar plates, to which doubling dilutions of penicillin, tetracycline, erythromycin, cefixime, ceftriaxone or co-trimoxazole were added.

\section{Serotyping}

The capsular polysaccharide type of pneumococci cultured from five patients were identified by the quellung reaction, using specific antisera obtained from the Staten Seruminstitut in Copenhagen.

\section{Patients}

The personal data and case history of all patients from whom a PRP was isolated during their stay at the pulmonary ward of the St. Joseph's Hospital were evaluated.

\section{Results}

\section{Spread of penicillin-resistant pneumococci}

The PRP was probably introduced by patient No. 2 (fig. 1). A PRP was cultured from this patient as early as 1989, during antibiotic treatment of purulent bronchitis. This patient was also admitted to the pulmonary ward in early and mid 1990, and sputum cultures then yielded PRP. During these admissions, no PRP were cultured from other patients.

From November 1990 to June 1991, PRP were cultured from 18 patients, 16 men with a mean age of $74 \pm 8$ yrs and two women aged 54 and 60 yrs (table 1). With the exception of one patient (No. 14), all male patients were aged $65 \mathrm{yrs}$ or more. Chronic obstructive pulmonary disease (COPD) was diagnosed in 16 patients, 10 of whom had an additional underlying disease (diabetes mellitus in 2, heart failure in 5 , and bronchial or urinary bladder carcinoma in 3 patients). Two patients were admitted with the single diagnosis of bronchial carcinoma. Prior to culture of PRP, 11 out of 18 patients were treated with antibiotics. In seven patients, this antibiotic was a beta-lactam antibiotic, in some cases in combination with an aminoglycoside. In five patients, co-trimoxazole was prescribed. Four patients from whom PRP were cultured did not have symptoms of pulmonary tract infection and, therefore, were not treated with antibiotics after isolation of PRP. In the remaining 14 patients, antibiotic treatment was initiated after culture of PRP because of clinical symptoms, laboratory tests and/or abnormalities on chest X-ray. In

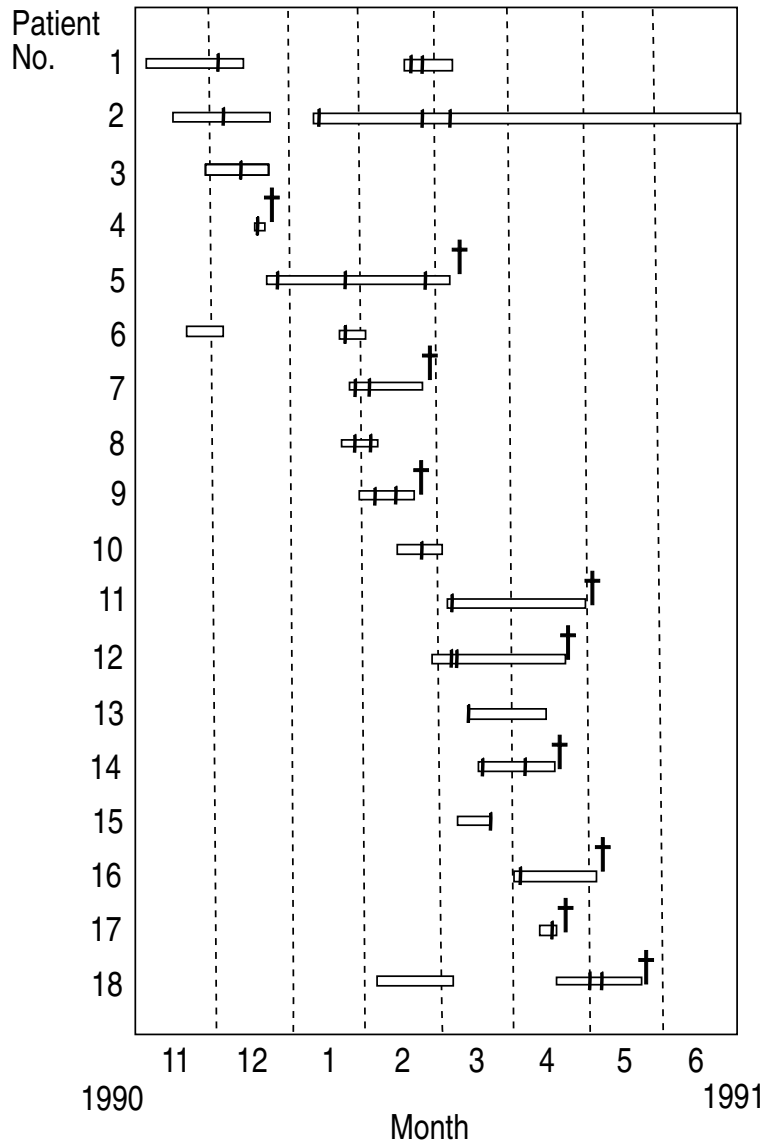

Fig. 1. - Admission and stay at the pulmonary ward of the St. Joseph's Hospital of patients from whom PRP: penicillin-resistant pneumococci.were cultured. $\mathrm{I}$ : = moment of isolation of PRP; $\dagger:=$ death.

nine patients, pneumococci were the only bacteria cultured from the sputum. In five patients, the sputum cultures yielded at least one additional respiratory pathogen. In all sputum samples, $>25$ leucocytes per low power field (lpf) were present on Gram staining. No serological investigations were performed to evaluate viral, ricketsial or chlamydial infection.

Two patients were treated exclusively with a betalactam antibiotic (patients Nos. 3 and 17), (table 1), and in four patients a beta-lactam antibiotic was changed to erythromycin, doxycycline or co-trimoxazole (patients Nos. 7, 9, 14 and 16). In three patients treatment with erythromycin was initiated after sputum cultures yielded PRP. In two of these co-trimoxazole was prescribed initially (patients Nos 11 and 12). Though sputum samples were not cultured routinely at regular intervals, the persistence of PRP despite antibiotic treatment could be documented in eight patients (patients Nos 1, 2, 5, $7,8,9,14$ and 18).

Finally, 10 out of 18 patients died during or shortly after hospitalization. In all of them there was a serious underlying disease (COPD in 9, and bronchial carcinoma in 1 patient). The death of one patient (patient No. 9) seems to be directly related to infection with PRP. On January 29th 1991, this patient was admitted to the pulmonary ward because of an exacerbation of 
Table 1. - Personal data, treatment and clinical outcome of patients $(n=18)$ with penicillin-resistant pneumococci (PRP)

\begin{tabular}{|c|c|c|c|c|c|c|c|}
\hline $\begin{array}{l}\text { Pt. } \\
\text { No }\end{array}$ & $\begin{array}{l}\text { Age } \\
\text { yrs }\end{array}$ & Sex & $\begin{array}{l}\text { Underlying } \\
\text { disease }\end{array}$ & $\begin{array}{l}\mathrm{AB} \text { before } \\
\text { isolation }\end{array}$ & RTI & $\begin{array}{l}\mathrm{AB} \\
\text { treatment }\end{array}$ & Course \\
\hline 1 & 80 & M & $\begin{array}{l}\text { COPD } \\
\text { DM }\end{array}$ & $\begin{array}{l}\text { amox./clav. } \\
\text { SXT, ceph. }\end{array}$ & + & cipro. & Deterioration \\
\hline 2 & 78 & M & $\begin{array}{l}\text { COPD } \\
\text { Dec. cordis. }\end{array}$ & pen., ceph. & + & $\begin{array}{l}\text { cipro. } \\
\text { clinda., CFM }\end{array}$ & Deterioration \\
\hline 3 & 54 & $\mathrm{~F}$ & $\begin{array}{l}\text { COPD } \\
\text { Dec. cordis. }\end{array}$ & $\begin{array}{l}\text { amox./clav. } \\
\text { genta. }\end{array}$ & + & pen. & Deterioration \\
\hline 4 & 77 & M & $\begin{array}{l}\text { COPD } \\
\text { Bronchus carc. } \\
\text { Dec. cordis }\end{array}$ & - & - & - & Deterioration, died \\
\hline 5 & 60 & $\mathrm{~F}$ & $\begin{array}{l}\text { COPD } \\
\text { Dec. cordis }\end{array}$ & - & - & - & Died \\
\hline 6 & 65 & M & $\begin{array}{l}\text { DM } \\
\text { COPD }\end{array}$ & SXT & + & SXT & Improvement \\
\hline 7 & 77 & M & COPD & CFM, tetra. & + & doxy., teico. & Died \\
\hline 8 & 83 & M & COPD & - & + & SXT & Improvement \\
\hline 9 & 65 & M & COPD & SXT & + & $\begin{array}{l}\text { CFM, genta. } \\
\text { pen., erythro. }\end{array}$ & Died \\
\hline 10 & 65 & M & Bronchus carc. & - & + & SXT, doxy. & Improvement \\
\hline 11 & 65 & $\mathrm{M}$ & Bronchus carc. & SXT & + & erythro. & $\begin{array}{l}\text { At first improvement, } \\
\text { died later }\end{array}$ \\
\hline 12 & 77 & M & $\begin{array}{l}\text { COPD } \\
\text { Vesical carc. } \\
\text { CVA }\end{array}$ & SXT & + & erythro. & $\begin{array}{l}\text { At first improvement, } \\
\text { died later }\end{array}$ \\
\hline 13 & 76 & M & $\begin{array}{l}\text { COPD } \\
\text { dec. cordis. }\end{array}$ & - & + & erythro & Improvement \\
\hline 14 & 63 & M & $\begin{array}{l}\text { COPD } \\
\text { dec. cordis } \\
\text { Kidney transpl. }\end{array}$ & - & + & $\begin{array}{l}\text { amox./clav. } \\
\text { CFM, } \\
\text { genta., erythro. }\end{array}$ & $\begin{array}{l}\text { At first improvement, } \\
\text { died later }\end{array}$ \\
\hline 15 & 78 & M & $\begin{array}{l}\text { COPD } \\
\text { sq. cell ca. }\end{array}$ & amox. & - & - & Recovered \\
\hline 16 & 79 & M & COPD & amox. & + & SXT, cipro. & $\begin{array}{l}\text { At first improvement, } \\
\text { died later }\end{array}$ \\
\hline 17 & 77 & M & COPD & amox. & + & amox. & Died \\
\hline 18 & 77 & M & COPD & - & - & - & Died \\
\hline
\end{tabular}

AB: antibiotic; amox.: amocycillin; Bronchus carc.: bronchial carcinoma; ceph: cephalosporin; CFM: cefuroxine; cipro.: ciprofloxacin; clav.: clavulanic acid; clind.: clindamycin; COPD: chronic obstructive pulmonary disease; CVA: cerebrovascular accident; CXM: cefixime; DB: diabetes mellitus; Dec. cordis: heart failure; doxy.: doxycycline; erythro.: erythromycin. genta.: gentamicin; Kidney transpl.: kidney transplant; pen.: penicillin; Sq. cell ca: squamous cell carcinoma; PRP: penicillin-resistant pneumococci; RTI: respiratory tract infection; SXT: sulphamethoxazole (co-trimoxazole); tetra.: tetracycline; teico.: teicoplanin. Vesical carc.: urinary bladder carcinoma.

Table. 2. - Minimal inhibitory concentrations (MICs, $\left.\mathrm{mg} \cdot \mathrm{l}^{-1}\right)$ ) of all isolated PRPs for penicillin, tetracycline, erythromycin, cefixime, ceftriaxone and co-trimoxazole

\begin{tabular}{rllllll}
\hline $\begin{array}{l}\text { Pt. } \\
\text { No. }\end{array}$ & Pen. & Tetra. & Erythro. & CXM & CRO4 & SXT \\
\hline 1 & 1.0 & 0.5 & 0.12 & $>4.0$ & 1.0 & $>8 / 40$ \\
2 & 1.0 & 0.5 & 0.06 & $>4.0$ & 0.5 & $>8 / 40$ \\
3 & 0.5 & 0.5 & 0.12 & $>4.0$ & 1.0 & $>8 / 40$ \\
4 & 0.5 & 0.5 & 0.06 & $>4.0$ & 0.5 & $>8 / 40$ \\
5 & 1.0 & 0.5 & 0.12 & $>4.0$ & 0.5 & $>8 / 40$ \\
6 & 1.0 & 0.5 & 0.06 & $>4.0$ & 1.0 & $>8 / 40$ \\
7 & 1.0 & 0.5 & 0.25 & $>4.0$ & 0.5 & $>8 / 40$ \\
8 & 1.0 & 0.5 & 0.06 & $>4.0$ & 0.5 & $>8 / 40$ \\
9 & 1.0 & 0.5 & 0.06 & $>4.0$ & 0.5 & $>8 / 40$ \\
10 & 1.0 & 0.5 & 0.12 & $>4.0$ & 0.5 & $>8 / 40$ \\
11 & 0.5 & 0.5 & 0.12 & $>4.0$ & 1.0 & $>8 / 40$ \\
12 & 1.0 & 0.5 & 0.12 & $>4.0$ & 1.0 & $>8 / 40$ \\
13 & 2.0 & 0.5 & 0.12 & $>4.0$ & 1.0 & $>8 / 40$ \\
14 & 1.0 & 0.5 & 0.06 & $>4.0$ & 0.5 & $>8 / 40$ \\
15 & 2.0 & 0.5 & 0.06 & $>4.0$ & 0.5 & $>8 / 40$ \\
16 & 1.0 & 0.5 & 0.06 & & 0.5 & $>8 / 40$ \\
17 & 1.0 & 0.5 & & & & $>8 / 40$ \\
18 & 1.0 & & 0.5 & & & \\
\hline
\end{tabular}

CRO: ceftriaxone. For further abbreviations see legend to table 1. 
COPD and fever up to $39^{\circ} \mathrm{C}$. Initially, treatment with co-trimoxazole seemed to result in clinical improvement and decrease in temperature. However, on February 6th, a second rise in temperature up to $39.4^{\circ} \mathrm{C}$ occurred. At that time, PRP were cultured from the blood and sputum, whilst on therapy with co-trimoxazole. On the chest X-ray, a lobar infiltrate was observed. In spite of treatment with cefuroxime (to which the isolate was demonstrated to be sensitive by disk diffusion testing) and gentamicin, and later erythromycin intraveneously, the patient deteriorated and died after 2 weeks of antibiotic therapy. A sputum culture taken at admission was negative for PRP.

In the other patients, a relationship between death and infection with PRP is hard to demonstrate because of the poor condition of these patients. In one patient, who did not have a pulmonary infection at admission and who was admitted because of psoriasis, infection with PRP caused a lobar pneumonia. He survived after treatment with erythromycin intravenously.

\section{Sensitivity testing and serotyping}

Using the quellung reaction, all five isolates of PRP that were available for testing were shown to be type 9 . The results of the MIC determinations are presented in table 2 .

The MICs of penicillin ranged $0.5-2.0 \mathrm{mg} \cdot \mathrm{l}^{-1}$. The MIC of tetracycline was invariably $0.5 \mathrm{mg} \cdot l^{-1}$. According to the guidelines issued by the Dutch Working Party on Standardisation of Sensitivity Testing (WRG), isolates inhibited by $\leq 1.0 \mathrm{mg} \cdot l^{-1}$ tetracycline are considered to be sensitive [14]. For erythromycin a breakpoint MIC of $1.0 \mathrm{mg} \cdot l^{-1}$ is advised by the WRG. The MIC of erythromycin varied between $0.06-0.12 \mathrm{mg} \cdot l^{-1}$, except for one strain isolated from patient No. 7 (MIC $\geq 16.0 \mathrm{mg} \cdot l^{-1}$ ). MICs of ceftriaxone were $0.5-1.0 \mathrm{mg} \cdot l^{-1}$ (breakpoint MIC $\left.4.0 \mathrm{mg} \cdot l^{-1}\right)$. The MIC of cefixime was $\geq 4.0 \mathrm{mg} \cdot l^{-1}$ for all isolates; according to the National Committee for Clinical Laboratory USA (NCCLS) the susceptibility limit for this oral cephalosporin is $1.0 \mathrm{mg} \cdot \mathrm{l}^{-1}$. All isolates tested had MICs $>8 / 40 \mathrm{mg} \cdot l^{-1}$ co-trimoxazole and were considered to be resistant to this combination of antibiotics.

\section{Discussion}

Spread of penicillin-resistant pneumococci within a hospital has been described previously. However, an outbreak of this extent has not been reported before [15-18]. In most cases - as in the present outbreak - the condition concerned elderly patients with an underlying disease, such as COPD, bronchial carcinoma and/ or diabetes mellitus. Heart failure, found in six patients, has not been reported before. Risk factors for carriership or invasive infections with PRP are the diseases mentioned above, as well as age above $70 \mathrm{yrs}$, immuno-suppression, and prior treatment with antibiotics, especially a beta-lactam antibiotic [8, 9, 19, 20]. In our patient group, the majority (11 out of 18 patients) were treated with antibiotics prior to isolation of PRP.
In six patients, the antibiotic was a penicillin or a cephalosporin.

Pneumococcal resistance to penicillin is not caused by the presence of beta-lactamase, but is caused by changes in penicillin-binding proteins. This implicates a decreased sensitivity for other beta-lactam antibiotics as well [21, 22].

In treatment of PRP, a distinction is made between pneumococci with a MIC $\leq 1.0 \mathrm{mg} \cdot l^{-1}$ and pneumococci with a MIC $>1.0 \mathrm{mg} \cdot l^{-1}$. The pneumococci mentioned above were shown to have MICs varying between 0.5$2.0 \mathrm{mg} \cdot l^{-1}$, indicating that such a distinction is arbitrary.

Upper respiratory tract infections and exacerbations of COPD by PRP are theoretically accessible to treatment with erythromycin. However, reports of erythromycin resistance in PRP are increasing [14, 23]. In The Netherlands, erythromycin resistance in pneumococci is still at a very low level [24].

Systemic infections with intermediately resistant pneumococci ( $\mathrm{MIC} \leq 1.0 \mathrm{mg} \cdot l^{-1}$ ) can be treated by high dose penicillin or third generation cephalosporins, such as cefotaxime and ceftriaxone $[9,19,25]$. In infections caused by highly resistant pneumococci (MIC $>1.0 \mathrm{mg} \cdot \mathrm{l}$ 1), treatment with high dose penicillin will often fail [9]. Some authors advise treatment with ceftriaxone or cefotaxime [26]. Due to change in penicillin-binding proteins, MICs of cephalosporins will also increase 10-20 fold, as demonstrated by the MIC results in table 2 . Treatment of patients with meningitis caused by high level penicillin-resistant pneumococci in particular may cause serious problems. Failure of treatment with cephalosporins has already been reported [27]. Chloramphenicol is not a good alternative because of a high failure rate, which is possibly caused by a low bactericidal activity against these pneumococci $[26,28]$. The only antibiotics to which even penicillin-resistant pneumococci remain susceptible are vancomvcin and teicoplanin [25].

Although interpretation of clinical outcome in this study is difficult because of the small number of patients and their serious underlying diseases, in most cases the frequent changing of antibiotics, and the death of one patient during therapy, indicate a very problematic treatment of our patient group. One patient was treated with teicoplanin, an antibiotic to which, like vancomycin, no resistance has been reported. However, these antibiotics are expensive and they can only be administrated intravenously.

Without any particular measures undertaken to contain the epidemic, the PRP have only been cultured occasionally since June 1992 and now seem to have disappeared completely. Nevertheless, a more stringent strategy seems to be indicated, considering the morbidity and cost that infections with these micro-organisms involve.

We suggest that patients from whom PRP have been cultured should be barrier nursed. In addition, all other patients on the same ward should be screened for carriership of the penicillin-resistant pneumococci $[15$, 29, 30]. In patients with the PRP, an attempt should be made to eradicate the bacteria by treatment with erythromycin (if proved susceptible), with or without 
rifampicin. In addition, mupirocin nasal ointment should be prescribed [29, 30].

Obviously, a strategy as mentioned above is only effective in countries with a low prevalence of PRP. In countries such as Spain or Hungary, in which up to $30 \%$ of all pneumococci are penicillin-resistant, isolation of individual patients has become senseless $[11,12]$.

The spread of penicillin-resistant pneumococci has repeatedly been linked to abundant antibiotic use, especially the frequent use of beta-lactam antibiotics [31]. It is, therefore, worth mentioning that the patient who is thought to have introduced the penicillin-resistant pneumococcus on the ward, was being treated in a clinical trial with a new oral cephalosporin when the resistant pneumococci were isolated for the first time. Because of their relatively unfavourable MICs oral cephalosporins may easily select less sensitive pneumococci.

Since the trend towards increase of penicillin resistance is expected to continue in the future, it may be necessary to follow a more active strategy with regard to pneumococcal vaccination of high risk patients. Possibly not only should asplenic patients be vaccinated but also patients with diabetes mellitus, the elderly and alcoholics [32].

\section{References}

1. Handwerger S, Tomasz A. Alterations in penicillinbinding proteins of clinical and laboratory isolates of pathogenic Streptococcus pneumoniae with low levels of penicillin resistance. J Infect Dis 1986; 153, (1): 83-89.

2. Hansman D, Bullen MM. A resistant pneumococcus. Lancet 1967; ii: 264-265.

3. Hansman D, Devitt L, Miles H, Riley I. Pneumococci relatively insensitive to penicillin in Australia and New Guinea. Med J Aust 1974; 2: 353-356.

4. Jacobs MR, Koornhof HJ, Robins-Browne RM, et al. Emergence of multiply resistant pneumococci. $N$ Engl J Med 1978; 299: 735-740.

5. Allen KD. Penicillin-resistant pneumococci. J Hosp Infect 1991; 17: 3-13.

6. Klugman KP, Koornhof HJ, Wasas A, Storey K, Gilbertson I. Carriage of penicillin-resistant pneumococci. Arch Dis Child 1986; 61: 877-881.

7. Michel J, Dickman D, Greenberg Z, Bergner-Rabinowitz $\mathrm{S}$. Serotype distribution of penicillin-resistant pneumococci and their susceptibilities to seven antimicrobial agents. Antimicrob Agents Chemother 1983; 23: 397401.

8. Mason EO, Kaplan SL, Lamberth LB, Tillman J. Increased rate of isolation of penicillin-resistant Streptococcus pneumoniae in a Children's Hospital and in vitro susceptibilities to antibiotics of potential therapeutic use. Antimicrob Agents Chemother 1992; 36: 1703-1707.

9. Istre GR, Tarpay M. Invasive disease due to Streptococcus pneumoniae in an area with a high rate of relative penicillin resistance. J Infect Dis 1987; 156: 732-735.

10. Geslin P, Fremaux A, Sissia G. Streptococcus pneumoniae: état actuel de la sensibilité aux beta-lactamines en France. Mise au point du Centre National de Réferences. Méd Mal Infect 1991; 21, Hors Série Mai: 3-11.

11. Linares J, Pallares R, Alonso $\mathrm{T}$, et al Trends in antimicrobial resistance of clinical isolates of Streptococcus pneumoniae in Bellvitge Hospital, Barcelona, Spain (1979-1990). Clin Infect Dis 1992; 15: 99-105.

12. Marton A. Pneumococcal antimicrobial resistance: the problem in Hungary. Clin Infect Dis 1992; 15: 106-111.

13. de Neeling AJ, Hemmes JH, van Klingeran B. Antimicrobial resistance in routine isolates of 7 Public Health Laboratories RIVM surveillance No. 253601001, 1993.

14. Mouton RP, van Klingeren B. Standaardisatie van gevoeligheidsbepalingen. RIVM, ISBN 96-6960-004-8, maart 1990.

15. Gould FK, Magee JG, Ingham HR. A hospital outbreak of antibiotic resistant Streptococcus pneumoniae. J Infect 1987; 15: 77-79.

16. Ridgway EJ, Allen KD, Galloway A, Rigby A, O'Donoghue M. Penicillin-resistant pneumococci in a Merseyside hospital. J Hosp Infect 1990; 17: 15-23.

17. Moore EP, Williams EW. Hospital transmission of multiply antibiotic-resistant Streptococcus pneumoniae. J Hosp Infect 1988; 16: 77-79.

18. Pallett AP, Strangeways JEM. Penicillin-resistant pneumococci. Lancet 1988; i: 1452.

19. Pallares R, Gudiol F, Linares J, et al. Risk factors and response to antibiotic therapy in adults with bacteremic pneumonia caused by penicillin resistant pneumococci. N Engl J Med 1987; 317: 18-22.

20. Ford KL, Mason EO, Kaplan SL, Lamberth LB, Tillman J. Factors associated with middle ear isolates of Streptococcus pneumoniae resistant to penicillin in a children's hospital. J Pediatr 1991; 119: 941-944.

21. Zighelboim S, Tomasz A. Multiple antibiotic resistance in South African strains of Streptococcus pneumoniae: mechanism of resistance to beta-lactam antibiotics. Rev Infect Dis 1981; 3: 267-276.

22. Linaros J, Alonso T, Pérez JL, A et al. Decreased susceptibility of penicillin-resistant pneumococci to twenty four $\beta$-lactam antibiotics. JAC 1992; 30: 279-288.

23. Anonymous. Penicillin-resistant pneumococci. Lancet 1988; i: 1142-1143

24. Endtz HP, Peetermans WEC, Bijlmer HA. Low frequency of erythromycin resistant Streptococcus pneumoniae in The Netherlands. Lancet 1989; i: 11441145.

25. Jacobs MR. Treatment and diagnosis of infections caused by drug-resistant Streptococcus pneumoniae. Clin Infect Dis 1992; 15: 119-127.

26. Viladrich PF, Gudiol F, Linares J, Rufi G, Ariza J, Pallares R. Characteristics and antibiotic therapy of adult meningitis due to penicillin-resistant pneumococci. Clin J Med 1988; 84: 839-846.

27. Bradley JS, Connor JD. Ceftriaxone failure in meningitis caused by Streptococcus pneumoniae with reduced susceptibility to beta-lactam antibiotics. Pediatr Infect Dis J 1991; 10: 871-873.

28. Friedland JR, Klugman KP. Recurrent penicillinresistant pneumococcal meningitis after chloramphenicol therapy. Pediatr Infect Dis J 1991; 10: 705-707.

29. Allen KD. Penicillin-resistant pneumococci. J Hosp Infect 1991; 17: 3-13.

30. Hausmann D, Devitt L, Miles H, Riley I. Pneumococci relatively insensitive to penicillin in Australia and New Guinea. Med J Aust 1974; 2: 353-356.

31. LaForce FM, Eickhoff TC. Pneumococcal vaccine: an emerging consensus. Ann Intern Med 1988; 108: 757-759.

32. Noah ND. Vaccination against pneumococcal infection. BMJ 1988; 297: 1351-1352. 